\title{
Continence in patients with spina bifida: long term results
}

\author{
Padraig S Malone, Robert A Wheeler, Jane E Williams
}

\begin{abstract}
One hundred and forty four questionnaires relating to bladder and bowel control were sent to a random selection of patients with spina bifida throughout the United Kingdom. One hundred and seventeen questionnaires were returned, of which 109 were usable. Twenty eight out of 109 responders had undergone some form of urinary diversion, of whom 20 (71\%) were reliably dry. The remaining 81 responders emptied their bladders by a variety of techniques including normal voiding, straining, expression, clean intermittent catheterisation, indwelling catheters, or they dribbled urine continuously. Only $31(38 \%)$ of this group were reliably dry. Ninety four of $109(86 \%)$ responders regularly sat on the toilet to evacuate their bowels and most used some aid such as manual evacuation, laxatives, suppositories, or enemas. Fifty five of 104 $(53 \%)$ responders soiled regularly, 31 $(56 \%)$ of whom were also wet. Forty seven per cent of dry patients (24/51) were faecally incontinent. Only 25 of 104 (24\%) patients responding to all questions were reliably clean and dry.

(Arch Dis Child 1994; 70: 107-110)
\end{abstract}

The surgical treatment of spina bifida and associated hydrocephalus ensures long term survival in most patients selected for treatment. The rapid realisation of the importance of appropriate management of the neuropathic bladder has led to most patients surviving with normal renal function. ${ }^{1}$ The goals of ongoing treatment are to enable patients to achieve their full potential, within the limits of their handicap, become fully integrated into society, and to be as independent as possible. A multidisciplinary approach from healthcare professionals, psychologists, educationalists, and other allied professions is required to achieve this end.

Incontinence is one of the major stigmata affecting their quality of life and producing dependence on others. Major advances have been made in the non-operative and operative management of urinary incontinence ${ }^{2-4}$ and faecal incontinence. ${ }^{5-8}$ These specialist centres report excellent results, but it seems that only a minority of patients have access to this treatment and most continue to suffer the socially isolating stigma of incontinence.

This study has attempted to assess the extent of the problem and the reasons underlying it by surveying a randomly selected group of patients with spina bifida in the community.

\section{Patients and methods}

Questionnaires were sent to 144 patients with spina bifida who were randomly selected from the computerised database of the Association for Spina Bifida and Hydrocephalus (ASBAH), which at the time contained just over 2000 names. The questionnaire addressed details of demography, medical care, and the methods and results of bladder and bowel management. Previous and planned specialist investigations and operative interventions were also assessed. Wherever possible the questionnaires were completed by the patients themselves, but if this was not possible, by their carers. The ASBAH fieldworkers explained the questionnaires and assisted in completion when required, but the answers always reflected the patient's views.

\section{Results}

One hundred and seventeen (81\%) of the 144 questionnaires were returned, 104 with all sections completed correctly and a further five with usable data, giving a study population of 109. The mean (range) age was $23 \cdot 5(9-47 \cdot 8)$ years with 67 females and 42 males. Sixty eight $(62 \%)$ patients were confined to a wheelchair and a further $27(25 \%)$ used one on occasions. Seventy six (70\%) patients had had a shunt fitted for hydrocephalus.

\section{ATTENDING CLINICIANS}

One hundred and one (93\%) patients saw their doctors regularly, $53(49 \%)$ every six months, $32(29 \%)$ annually, and $16(15 \%)$ at regular intervals of more than one year. Fifty four $(50 \%)$ patients saw more than one doctor and $14(13 \%)$ saw three or more (table 1$)$.

\section{BLADDER FUNCTION}

Twenty eight $(26 \%)$ patients had had some form of urinary diversion, one after unsuccessful bladder reconstruction. The mean (range)

Table 1 Clinicians playing a part in the long term follow up of patients in the survey

\begin{tabular}{lc}
\hline Clinician & No of patients \\
\hline General practitioner & 80 \\
Urologist & 34 \\
Unspecified hospital consultant & 22 \\
Nephrologist & 11 \\
Neurologist & 10 \\
Paediatric or general surgeon & 9 \\
Neurosurgeon & 8 \\
Orthopaedic surgeon & 9 \\
Spina bifida clinic doctor & 3 \\
Paediatrician & 1 \\
Haematologist & 1
\end{tabular}


Table 2 Urinary control $(n=109)$. Values are number (\%)

\begin{tabular}{lcc}
\hline Method of management & Wet & Dry \\
\hline Urinary division $(\mathrm{n}=28)$ & $8(29)$ & $20(71)$ \\
Voiding $(\mathrm{n}=21)$ & $6(29)$ & $15(71)$ \\
Clean intermittent catheterisation & & \\
$\quad(\mathrm{n}=23)$ & $16(70)$ & $7(30)$ \\
Indwelling catheter $(\mathrm{n}=16)$ & $11(69)$ & $5(31)$ \\
Expression $(\mathrm{n}=10)$ & $6(60)$ & $4(40)$ \\
Dribbling $(\mathrm{n}=11)$ & $11(100)$ & $0(0)$ \\
Total & $58(53)$ & $51(47)$ \\
\hline
\end{tabular}

age at diversion was $11(1-30)$ years and 12 (43\%) patients needed revision surgery, on one occasion in 10 patients, and on four and 10 occasions in the other two. Twenty $(71 \%)$ of the patients who had had urinary diversion were dry day and night. Seven $(25 \%)$ were regularly wet day and night and one was wet at night only. Twenty four ( $86 \%$ ) patients said they were 'happy' with their diversions, although $12(43 \%)$ knew of no alternative management. Sixteen $(57 \%)$ patients had had a mean (range) of six (one to 12) urinary infections in the previous 12 months:

Of the other 81 patients, $23(28 \%)$ practised clean intermittent catheterisation, $21(26 \%)$ voided 'normally', 16 (20\%) had an indwelling catheter, $10(12 \%)$ manually expressed, and $11(14 \%)$ dribbled urine continuously.

Of the 23 patients practising clean intermittent catheterisation, $20(87 \%)$ were selfcatheterising and $16(70 \%)$ catheterised more frequently than every four hours. Seven $(30 \%)$ patients were dry day and night, $13(57 \%)$ were wet all the time, and three $(13 \%)$ were only wet at night. Of the 21 normally voiding patients, $15(71 \%)$ were dry and the others wet day and night. Five of $16(31 \%)$ patients using an indwelling catheter were dry whereas the others suffered frequent wet episodes due to catheter blockage. Four $(40 \%)$ of the 10 patients using manual expression were dry. In this group as a whole $31(38 \%)$ were reliably dry day and night (table 2). When asked to categorise the degree of wetting 10 patients said they were 'damp', 22 'wet', and 16 'soaked'. Eleven patients wore nappies, 26 midi pads and seven mini pads.

Of the 31 dry patients, four (13\%) had had bladder augmentation, three with an artificial urinary sphincter and one with a Mitrofanoff procedure, ${ }^{9}$ to facilitate clean intermittent catheterisation. One further patient had had a sphincterotomy and two patients were receiving adjuvant treatment with oxybutynin.

Of the 50 wet patients, five $(10 \%)$ had a previous sphincterotomy, one had had an unsuccessful bladder neck suspension, and a further patient had been undiverted. One patient was awaiting bladder augmentation and insertion of an artificial urinary sphincter. Ten $(20 \%)$ patients were receiving adjuvant oxybutynin (or its equivalent). Fourteen $(28 \%)$ patients had had urodynamic investigations on one or more occasions.

BOWEL CONTROL

Ninety four of $104(86 \%)$ patients regularly sat on the toilet and attempted defaecation; 10
(10\%) used exercises to aid emptying, 26 (25\%) patients practised manual evacuation, $25(24 \%)$ regularly used laxatives, and 13 $(13 \%)$ used suppositories or enemas, or both, but it was impossible to say which type of enema was used.

Fifty five of 104 (53\%) patients regularly soiled: staining of underwear or pad in 12 $(22 \%)$, 'moderate' soiling in $25(45 \%)$, and 'severe' in 18 (33\%). Forty nine (89\%) used some form of 'protection': 12 (24\%) nappies, $31(63 \%)$ midi pads, and six $(12 \%)$ mini pads. Of the 64 patients practising manual evacuation or using drugs $32(50 \%)$ soiled, as did $23 / 40(58 \%)$ using no treatment.

Information on both bladder and bowel function was available in 104 patients. Of the $49(47 \%)$ patients who did not soil $24(49 \%)$ were wet. Of the 51 dry patients in the whole group $24(47 \%)$ soiled. Thirty one $(30 \%)$ patients in the whole group of 104 had both urinary and faecal incontinence whereas 25 $(24 \%)$ patients were both clean and dry (table 3).

\section{Discussion}

Although this study has all the drawbacks of postal surveys with incomplete response rates, it has uncovered an indisputably high incidence of incontinence. Seventy six per cent of patients were incontinent; $30 \%$ were doubly incontinent, $23 \%$ had isolated urinary incontinence, and $23 \%$ had faecal incontinence. The most successful treatment for urinary incontinence was a urinary diversion with a $71 \%$ continence rate. Many studies, however, have now shown significant renal deterioration in up to $48 \%$ of patients with a diversion, ${ }^{10-12}$ and this can no longer be accepted as a routine first line treatment for incontinence in the neuropathic bladder. With this decreasing use of urinary diversion incontinence rates could be expected to increase even higher, so it is imperative to study the possible causes of such disappointing results.

When the 50 patients who were urinary incontinent but who had not had diversion treatment were analysed separately, some interesting features were highlighted. Only 14 (28\%) patients had ever had urodynamic studies, though it has been clearly shown that these are essential if conservative treatment of the neuropathic bladder is to be rationally and selectively applied. ${ }^{13} 14$ Since the introduction of clean intermittent catheterisation by Lapides $e \mathrm{al}^{2}$ in 1972 it has become one of the cornerstones of management of the neuropathic bladder, with continence rates as high as $92 \%$ reported in long term studies. ${ }^{15}$ Only 23

Table 3 Combined faecal and urinary control $(n=104)$. Values are number (\%)

\begin{tabular}{llll}
\hline \multirow{4}{*}{ Urinary status } & \multicolumn{3}{l}{ Faecal status } \\
\cline { 2 - 4 } & Soiled & Clean & Total \\
\hline Wet & $31(30)$ & $24(23)$ & $55(53)$ \\
Dry & $24(23)$ & $25(24)$ & $49(47)$ \\
Total & $55(53)$ & $49(47)$ & 104 \\
\hline
\end{tabular}


$(21 \%)$ patients in this study were practising clean intermittent catheterisation, of whom 16 $(70 \%)$ remained wet, a figure well above reported results. Only six of these patients had had urodynamic studies and the lack of this investigation may possibly explain this high rate of incontinence by inappropriate patient selection. The use of pharmacological agents such as oxybutynin, used either alone or in combination with clean intermittent catheterisation, can improve continence in some patients ${ }^{3}$ but only $10(20 \%)$ of these urinary incontinent patients were using or had tried such treatment. Pharmacological treatment should be used selectively based on urodynamic findings; oxybutynin is useful if hyperreflexia is present and ephedrine hydrochloride may be tried in patients with mild sphincter weakness incontinence.

Operations for bladder reconstruction can be successful in managing neuropathic incontinence, with success rates in excess of $90 \%$ reported. ${ }^{4}$ Only two of these incontinent patients had had an operation, however, and one patient was awaiting reconstruction. A wide range of reconstructive procedures is available. The small capacity, poorly compliant/hyperreflexic bladder can generally be augmented using intestinal segments, or megaureters if they are present. The bladder outlet resistance can be enhanced either by suspension procedures, urethral lengthening, bladder neck reconstruction, or artificial urinary sphincters. If urethral clean intermittent catheterisation is not practical it may be facilitated by the construction of a continent catheterisable abdominal stoma - the Mitrofanoff procedure. ${ }^{9}$ This entails implanting the appendix (as in ureteric reimplantation) into the bladder and bringing the other end to the skin as an abdominal stoma. This procedure is particularly suitable for patients confined to a wheelchair.

The situation was similar with respect to faecal incontinence. Although 94/104 (86\%) patients regularly sat on the toilet and attempted evacuation, only $64(62 \%)$ used any form of adjuvant treatment such as manual evacuation, laxatives, suppositories, or enemas. Even for those patients using adjuvant treatment $32(50 \%)$ continued to soil, indicating the inadequacy of this treatment. In 1987 Shandling and Gilmour described the use of the enema continence catheter in 112 patients with spina bifida and all were clean. ${ }^{5}$ Only one patient in this study used the continence catheter and although a further 12 patients were using either suppositories or enemas, it was impossible to say which type. Even if all these patients used the enema continence catheter it would still represent only $13 \%$ of the study group, a very low take up for such a successful treatment. An operation has been developed in which the appendix is used to provide continent catheterisable access to the caecum, through which antegrade continence enemas (ACE procedure) can be administered; results are excellent in patients with spina bifida. ${ }^{6-8}$ Although an operation is required this technique is less cumbersome and easier to use than the enema continence catheter and even some of Shandling's patients have changed to the ACE procedure (B Shandling, personal communication, 1992). If patients are to be offered the best chance of being clean these newer methods of treatment should always be considered as an option. We would stress, however, that regular toilet training and careful attention to dietary measures from an early age may produce excellent results and prevent the development of secondary megarectum/colon and thus obviate the need for these more invasive measures.

It is difficult to explain why so many patients do not have access to modern investigation and treatment, and this is one of the drawbacks of the postal survey. It is possible that many did not want or were not suitable for more intensive investigation and management, but clinical experience suggests otherwise. Reports ${ }^{16-17}$ have suggested that incontinent patients are either unaware of, or have not availed themselves of, the appropriate services. In 1992 Briggs and Williams stated '... a large burden of need is not being met, even when services are available. The reasons for this are not clear and the issue merits further attention.' ${ }^{17}$ We believe that this study shows a similar situation for incontinent patients with spina bifida.

Patients with spina bifida have many problems and require a multidisciplinary approach to their management: paediatricians, paediatric surgeons, neurosurgeons, urologists, orthopaedic surgeons, and many others (table 1). All these services require careful coordination and there is little doubt that the best person to provide this care in childhood is an interested paediatrician. When patients are too old to attend paediatricians, many enter a state of limbo and we believe that they may be lost to regular hospital supervision during this transition. It is therefore essential that the patient's multiple problems should be optimally managed during childhood in an attempt to avoid the disappointing results seen in this survey. The onus therefore rests with the paediatric specialists to familiarise themselves with the advances being made in different specialties to provide a modern comprehensive service for their patients. The management of incontinence is one area where major improvements are possible, but life long follow up is also essential to ensure the preservation of renal function.

It is important that bowel and bladder function should be managed simultaneously and not in isolation. Every attempt should be made to train patients at a normal age, but if this is not successful further investigation and treatment should then be considered. Urodynamic facilities are freely available in most centres, as are the services to teach and support clean intermittent catheterisation. The urodynamic studies would help to select appropriate patients and identify those in whom adjuvant treatment may be helpful. At the same time conservative treatment such as laxatives, suppositories, or enemas (including the enema continence catheter) may be introduced for the bowels. If these conservative methods are unsuccessful, then more aggressive approaches 
should be considered, and this would entail the involvement of an interested paediatric surgeon or a urologist, or both. Surgical intervention should only be undertaken when there is a clear understanding by all involved of the nature of the operation and patients and parents are motivated to be clean and dry. No patient with spina bifida who wants to be continent and out of nappies should be denied the opportunity of discussing and considering all the options available, even though at the end of the day they may postpone a definitive decision until later. Paediatric specialists must also try to ensure that their patients are transferred to appropriate adult specialists when they are too old to avail of children's services. We believe that if these simple measures are followed, considerable improvement in patient care, particularly with respect to incontinence, could follow.

We thank the Association for Spina Bifida and Hydrocephalus for providing access to their database and financial support for
this study. We also thank their field workers for their invaluable assistance.

1 Woodhouse CJR, Neuropathic bladder. In: Woodhouse CJR, ed. Longterm paediatric urology. London: Blackwell Scientific, 1991: 70-9.

2 Lapides J, Diokno AC, Silber SJ, Lowe BS. Clean, intermittent self-catheterisation in the treatment of urinary tract disease. F Urol 1972; 107: 458-61.
3 Borzyskowski M, Mundy AR, Neville BGR, et al. Neuropathic vesicourethral dysfunction in children. $\mathrm{Br} \mathcal{F}$ Urol 1982; 54: 641-4.

4 Nurse DE, Britton JP, Munday AR. Relative indications for orthotopic lower urinary tract reconstruction, continent orthotopic lower urinary tract reconstruction, continent urinary diversion

5 Shandling B, Gilmour RF. The enema continence catheter in spina bifida: successful bowel management. $\mathcal{F}$ Pediatr Surg 1987; 22: 271-3.

6 Malone PS, Ransley PG, Kiely EH. Preliminary report: the antegrade continence enema. Lancet 1990; 336: 1217-8.

7 Wheeler RA, Malone PS. Use of the appendix in reconstructive surgery: a case against incidental appendicectomy. Br $\mathcal{Y}$ Surg 1991; 78: 1283-5.

8 Squire R, Kiely EM, Carr B, Ransley PG, Duffy PG. The clinical application of the Malone antegrade colonic clinical application of the Malone ant

9 Mitrofanoff P. Cystostomie continente trans-appendiculare dans le traitement des vessies neurologiques. Chir Pediatr dans le traitement

10 Elder DD, Moisey C, Rees RW. A long term follow up of the colonic conduit operation in children. $B r \mathcal{F}$ Urol 1979; 51: $462-5$

11 Hill JT, Ransley PG. The colonic conduit: a better method of urinary diversion? Br $\mathcal{f}$ Urol 1983; 55: 629-31.

12 Hussmann DA, McLorie GA, Churchill BM. Nonrefluxing colonic conduits: a long-term life-table analysis. 7 Urol 1989; 142: 1201-3.

13 Mundy AR, Borzyskowski M, Saxton HM. Videourodynamic evaluation of neuropathic vesicourethral urodynamic evaluation of neuropathic vesicouret

14 Rickwood AMK, Thomas DG, Philp N, Spicer RD. Assessment of congenital neuropathic bladder by combined urodynamic and radiological studies. $\mathrm{Br} F \mathrm{Urol}$ 1982; 54: 502-11.

15 Wyndaele JJ, Maes D. Clean intermittent catheterisation: a 12 year follow up. $\mathcal{f}$ Urol 1990; 143: 906-8.

16 O'Brien J, Austen M, Sethi P, O'Boyle P. Urinary incontinence: prevalence, need for treatment, and effectiveness of intervention by nurse. $B M \mathcal{F} 1991 ; 303: 1308-12$.

17 Briggs $M$, Williams ES. Urinary incontinence [letter]. $B M F$ 1992; 304: 255. 